\title{
No Evidence of HSV Presence in the Serum of Vitiligo Patients
}

\author{
Zhe Liu ${ }^{1,2}$, Rui-Qun Qi ${ }^{1}$, Lian-Shuang Zhao ${ }^{3}$, Xiao-Dong Sun ${ }^{1}$, Da-Yong Dong ${ }^{4}$, Gui-Hua Li ${ }^{1}$, Ya-Ni Lv ${ }^{1}$, Long Geng ${ }^{1}$, Hong-Duo Chen ${ }^{1}$ and Xing-Hua Gao ${ }^{1 *}$ \\ ${ }^{1}$ Department of Dermatology, No. 1 Hospital of China Medical University, 155 North Nanjing Street, Shenyang 110001, China \\ ${ }^{2}$ Department of Dermatology, Central Hospital of Shenyang Sujiatun District, 31 Begonia Street, Sujiatun District, Shenyang 110101, China \\ ${ }^{3}$ Department of Clinical Laboratory, No. 1 Hospital of China Medical University, 155 North Nanjing Street, Shen yang 110001, China \\ ${ }^{4}$ State Key Laboratory of Pathogens and Biosecurity, Beijing Institute of Microbiology and Epidemiology, 20 Feng Tai Dongdajie Street, Beijing 100071, PR China
}

*Corresponding author: Xing-Hua Gao, Department of Dermatology, No. 1 Hospital of China Medical University, 155 North Nanjing Street, Shenyang 110001 , China, Tel: +86-24-83282525, Fax: +86-24-83282525; E-mail: gaobarry@hotmail.com

Rec date: April 09, 2014; Acc date: May 23, 2014; Pub date: May 25, 2014

Copyright: () Liu Z 2014, This is an open-access article distributed under the terms of the Creative Commons Attribution License, which permits unrestricted use, distribution, and reproduction in any medium, provided the original author and source are credited.

\begin{abstract}
Vitiligo is mostly regarded as a consequence of autoimmune response, while the triggering factors remain to be determined. We checked the presence of HSV specific DNA, and IgG and IgM antibodies against HSV, in serum of 90 vitiligo patients by PCR and chemiluminescence methods, respectively. No HSV specific DNA was detected in vitiligo of any types or stages. The seropositivity of antibodies against HSV was similar between the patients and controls. Other approaches should be tried to clarify the role of HSV in the pathogenesis of vitiligo.
\end{abstract}

Keywords: Vitiligo; Serum; Herpes simplex virus; Polymerase chain reaction

\section{Introduction}

Vitiligo is an acquired disease characterized by chromic macules due to the absence of melanocytes. The proposed pathogenesis of vitiligo relates to genetics, neurochemical factors, self-destruction of melanocytes and autoimmunity, etc. [1]. The fact that there are roughly patterned clinical distributions of vitiligenous lesions that conforms to different clinical types of vitiligo suggest different etiological or pathophysiological pathways involved in the disease. Iverson noted that infection by herpes viridae family somewhat matched the symptoms of vitiligo, and he postulated that the infection might be a trigger for the disease [2]. Indeed, a study by Grimes et al found that $38 \%$ of vitiligo specimen (12 out 29 specimens) harbored cytomegalovirus specific DNA, but negative for DNAs of herpes simplex, varicella-zoster, Epstein-Barr, HIV, and human T-cell lymphotropic virus, though the relatively small size of the cohorts limited the power of the study.[3] Adiloglu et al. [4] detected higher rate of serum anti human herpes virus 6 IgG in vitiligo patients than in the controls, suggesting a tentative role of HSV 6 infection in vitiligo. So far, there have been no definite reports on association of herpes simplex virus(HSV) with vitiligo patients. Interestingly, a high proportion of Smyth line chicken inoculated with HSV vaccine developed autoimmune vitiligo [5].

HSV is a neurotropic virus. It typically causes herpes simplex when the immunity is low [6]. HSV infection is also blamed to cause erythema multiforme, a self-limiting erythro-papular inflammatory condition typically affecting hands, feet and facial-mucosal regions. HSV specific DNA could be detected in 15/22 of keratinocytes of erythema multiforme lesions $[7,8]$. The reason of relatively site specific invasion of HSV remains obscure. Acra-facial vitiligo is a clinical type of vitiligo. Patients develop de-pigmentary lesions mostly on face, hands and/or feet, or on mucosa [9]. Due to the close similarities of clinical distribution of lesions between acro-facial vitiligo and erythema multiforme, we postulated that HSV might be a common trigger for both conditions, albeit with different targets (keratinocytes vs melanocytes), or mechanisms of immunological responses and/or clinical-pathological outcomes. To test this hypothesis, we detected serum HSV specific DNA in different clinical types of vitiligo by PCR. Sera positive detection of HSV DNA reflects the occurrence of acute clinical herpes simplex [10]. In addition, we also measured anti HSV antibodies to delineate the acquisition of HSV infection in the patients and controls.

\section{Materials and Methods}

We enrolled ninety outpatients (male 42 , female 48 ) with clinically diagnosed vitiligo during 2009 and 2010, upon obtaining informed consents. All patients completed the questionnaire regarding the age of onset, duration of the disease, afflicted sites and family history. The VIDA scoring system was used to define the stages of patients with vitiligo. Active vitiligo refers to expansion of existing lesions and appearance of new lesions. Scores over one refer to that the disease is active in different time period in a year. Score of zero refers to stable over a year [11]. Data on serum HSV Ab screening tests for 724 pregnancy women were used as a sero-prevalence control. The control groups were pregnant women at early gestational age (younger than three months old) undergoing TORCH test. They were enrolled sequentially during the year of 2009 to 2010. Five patients with acute onset of herpes simplex were also included in the study.

We collected serum from the vitiligo and herpes simplex patients (2 genital herpes, 3 facial herpes). In addition, lesional scrapes were also collected from the herpes simplex patients. As previously reported, we amplified HSV DNA by PCR, using the follow primers: sense, 5'TCAAGGCCACCATGTACTACAAAGACGT antisense, 5'GCCGTAAAACGGGGACATGTACACAAAGT. The amplification conditions were $94^{\circ} \mathrm{C}$ denaturation for 30 seconds, $55^{\circ} \mathrm{C}$ annealing for 30 seconds, $72^{\circ} \mathrm{C}$ elongation for 1 minute. After 35 cycles of amplification, the PCR products were ran on 2\% agarose gel [12-14]. Antibodies against herpes simplex virus in serum of patients were detected by chemiluminescence method using Dia Sorin LIAISON @ 
type2229 (Reagents: LIAISON @ HSV-1/2IgG, product number 310800; LIAISON @ HSV-1/2IgM, product number 310820). SPSS software (19.0 version) was used to generate data for statistical testing ( $\mathrm{T}$ test). $\mathrm{P}<0.05$ was considered statistically significant.

\section{Results}

Among the 90 enrolled vitiligo patients, their ages ranged from 4 to 70 years and duration of the disease ranged from two weeks to 19 years. $80 \%$ of patients were over the age of 16 . According to sites of affliction, there were two cases of universal type, six cases of segmental type, seven cases of localized type, 50 cases of vitiligo vulgaris and 25 cases of acro-facial type. 79 cases were in progressive stage, 11 in stable stage. 23 of the 90 patients had a family history of vitiligo. The control group was at the age of 16 to 42. As shown in Table 1, HSV IgM antibody was detected in a case of acral-facial and a case of segmental vitiligo $(2.22 \%)$, both of the patients were at progressive stage. The acral-facial vitiligo patient was a 31- year old man with disease duration of 5 months; the segmental vitiligo patient was a 30 -year old lady with disease duration of 5 months. There was no statistical difference of seropositivity between patients of progressive and stable stages, respectively $(\mathrm{p}>0.05) .84$ out of 574 pregnant women undergoing screen test were HSV IgM positive (14.63\%). 78 (86.67\%) vitiligo patients were HSV IgG positive, and 134 out of 150 pregnant women undergoing screen test were HSV IgG positive (89.33\%). There were no statistical differences between the patients and controls (all $\mathrm{P}>0.05)$. Of the 23 patients with family history of vitiligo, 15 of them (65.1\%) showed seropositivity of HSV IgG. From these data, it seems humoral immune response against HSV had no role in the pathogenesis of vitiligo. No HSV DNA was detected in 90 cases of vitiligo patients. No HSV DNA was detected from serum of the five herpes simplex patients. HSV DNA was detected in three of five lesional scrapes of the herpes patients.

\begin{tabular}{|l|l|l|l|l|l|l|}
\hline Type & $\begin{array}{l}\text { Number } \\
\text { of } \\
\text { patients }\end{array}$ & $\operatorname{lgM}(+)$ & $\operatorname{lgG}(+)$ & $\begin{array}{l}\text { Progressiv } \\
\text { e } \\
\text { (positive } \\
\text { No./No. of } \\
\text { patients) }\end{array}$ & $\begin{array}{l}\text { Stable } \\
\text { (positive } \\
\text { No./No. } \\
\text { of } \\
\text { patients) }\end{array}$ & $\begin{array}{l}\text { Total \% of } \\
\text { sero- } \\
\text { positivity }\end{array}$ \\
\hline Universal & 2 & 0 & 1 & $1 / 2$ & 0 & $50 \%$ \\
\hline Segmental & 6 & 1 & 5 & $6 / 6$ & 0 & $100 \%$ \\
\hline Localized & 7 & 0 & 5 & $2 / 3$ & $3 / 4$ & $71.4 \%$ \\
\hline Vulgaris & 50 & 0 & 46 & $41 / 45$ & $5 / 5$ & $92 \%$ \\
\hline Acro-facial & 25 & 1 & 21 & $20 / 23$ & $2 / 2$ & $88 \%$ \\
\hline Sum & 90 & 2 & 78 & $70 / 79$ & $10 / 11$ & $88.9 \%$ \\
\hline
\end{tabular}

Table 1: Seroprevalence of HSV in different types of vitiligo

\section{Discussion}

There are prevailing evidences supporting the association of vitiligo with autoimmunity. Susceptibility genes include HLA, PTPN22, NALP1 and perhaps CTLA4 $[15,16]$. While the triggering factors remains largely unknown. There was a low incidence of vitiligo in the absence of turkey herpes virus (HVT) vaccination and a high incidence of vitiligo when Smith line chickens were vaccinated with HVT at hatch. T lymphocytes infiltrating depigmentation spots strongly support that HVT as an environmental factor to stimulate the vitiligo autoimmune response [5]. The distribution pattern of acralfacial vitiligo is similar to erythema multiforme, a condition in a proportion of which there harbored HSV in lesional skin and serum [17]. The most common type of Erythema multiforme is pimples-rash type. It has symmetrical distribution of lesions on hand, foot and back, forearm, ankle, etc. the natural course of the disease is about 2-4 weeks [18]. The fact that erythema multiforme has a definite and acute onset, while vitiligo has an insidious and slow onset may account for the negative detection of HSV in vitiligo serum, as evidenced by study that HSV was no long detected in patients several weeks after clinical resolution[12]. Infection of herpes simplex virus may have already recovered in the long course of vitiligo, and converted to other mechanisms that played the subsequent roles, such as autoimmunity. As shown in the Table 1, six patients of segmental type were at progressive stage. All of them were sero-positive for IgG. The distribution of segmental vitiligo along the peripheral nerve route provides another hint of HSV involvement. A large cohort of study is required to consolidate this finding.

There are reports that though pregnancy may change the humoral responses, the seroprevalence in pregnant women is similar to the general population. [19] We thus take the advantage of a screening programme for TORCH agents in pregnant women in our hospital as control group.

Theoretically, due to the high sensitivity of PCR, we do expect a 5/5 detection of HSV DNA in the samples. Actually, the detection rate is often influenced by duration of the disease, morphology of the lesions $[13,14]$ Although we failed to detect herpes virus DNA in the serum of patients with vitiligo ( even in serum of acute onset herpes simplex), the relationship between vitiligo and the herpes simplex virus still deserves attention. Other approaches, such as detection of persistent and sensitive markers of HSV activation or HSV specific T cell mediated responses, may aid to define the role of HSV in vitiligo. The other tangible approach is to detect HSV DNA in the lesion of vitiligo, though there is risk of negative results due to the insidious nature of the virus.

\section{Acknowledgement}

This work was supported by Public welfare Programme, Ministry of Health, China(201202013), and Innovative research team in universities, Liaoning Bureau of Education(LT2012012)

\section{References}

1. Yaghoobi R, Omidian M, Bagherani N (2011) Vitiligo: a review of the published work. J Dermatol 38: 419-431.

2. Iverson MV (2000) Hypothesis: vitiligo virus. Pigment Cell Res 13: 281-282.

3. Grimes PE, Sevall JS, Vojdani A (1996) Cytomegalovirus DNA identified in skin biopsy specimens of patients with vitiligo. J Am AcadDermatol 35: 21-26.

4. Adiloglu AK, Basak PY, Can R, Akkaya VB (2005) Vitiligo and human herpesvirus 6. Is there a relationship? Saudi Med J 26: 492-494.

5. Erf GF, Bersi TK, Wang X, Sreekumar GP, Smyth JR Jr (2001) Herpesvirus connection in the expression of autoimmune vitiligo in Smyth line chickens. Pigment Cell Res 14: 40-46.

6. Meylan P (2011) [Herpes simplex virus infections, an update for the practitioner]. Rev Med Suisse 7: 886-888, 890-3.

7. Umbach JL, Kramer MF, Jurak I, Karnowski HW, Coen DM, et al. (2008) MicroRNAs expressed by herpes simplex virus 1 during latent infection regulate viral mRNAs. Nature 454: 780-783. 
Citation: Liu Z, Qi RQ, Zhao LS, Sun XD, Dong DY, et al. (2014) No Evidence of HSV Presence in the Serum of Vitiligo Patients. Pigmentary Disorders 1: 105. doi:10.4172/jpd.1000105

Page 3 of 3

8. Brice SL, Krzemien D, Weston WL, Huff JC (1989) Detection of herpes simplex virus DNA in cutaneous lesions of erythema multiforme. J Invest Dermatol 93: 183-187.

9. Mchepange UO, Gao XH, Liu YY, Liu YB, Ma L, et al. (2010) Vitiligo in North-Eastern China: An association between mucosal and acrofacial lesions. ActaDermVenereol 90: 136-140.

10. Youssef R, Shaker O, Sobeih S, Mashaly H, Mostafa WZ (2002) Detection of herpes simplex virus DNA in serum and oral secretions during acute recurrent herpes labialis. J Dermatol 29: 404-410.

11. Njoo MD, Das PK, Bos JD, Westerhof W (1999) Association of the Köbner phenomenon with disease activity and therapeutic responsiveness in vitiligo vulgaris. Arch Dermatol 135: 407-413.

12. Brice SL, Stockert SS, Jester JD, Huff JC, Bunker JD, et al. (1992) Detection of herpes simplex virus DNA in the peripheral blood during acute recurrent herpes labialis. J Am AcadDermatol 26: 594-598.

13. Scoular A, Gillespie G, Carman WF (2002) Polymerase chain reaction for diagnosis of genital herpes in a genitourinary medicine clinic. Sex Transm Infect 78: 21-25.
14. Cohen BA, Rowley AH, Long CM (1994) Herpes simplex type 2 in a patient with Mollaret's meningitis: demonstration by polymerase chain reaction. Ann Neurol 35: 112-116.

15. Spritz RA (2008) The genetics of generalized vitiligo. CurrDirAutoimmun 10: 244-257.

16. Boissy RE, Spritz RA (2009) Frontiers and controversies in the pathobiology of vitiligo: separating the wheat from the chaff. ExpDermatol 18: 583-585.

17. Imafuku S, Kokuba H, Aurelian L, Burnett J (1997) Expression of herpes simplex virus DNA fragments located in epidermal keratinocytes and germinative cells is associated with the development of erythema multiforme lesions. J Invest Dermatol 109: 550-556.

18. Scully C, Bagan J (2008) Oral mucosal diseases: erythema multiforme. Br J Oral MaxillofacSurg 46: 90-95.

19. Hettmann A, Gerle B, Barcsay E, Csiszár C, Takács M (2008) Seroprevalence of HSV-2 in Hungary and comparison of the HSV-2 prevalence of pregnant and infertile women. ActaMicrobiolImmunol Hung 55: 429-436. 